\title{
The consequences of introducing stochasticity in nutrient utilisation models: the case of phosphorus utilisation by pigs
}

\author{
V. Symeou, I. Leinonen and I. Kyriazakis* \\ School of Agriculture, Food and Rural Development, Newcastle University, Newcastle upon Tyne NE1 7RU, UK \\ (Submitted 16 July 2015 - Final revision received 5 October 2015 - Accepted 15 October 2015 - First published online 26 November 2015)
}

\section{Abstract}

Simulation models of nutrient utilisation ignore that variation in pig system components can influence the predicted mean and variance of the performance of a group of pigs. The objective of this study was to develop a methodology to investigate how variation in feed composition would (a) affect the outputs of a nutrient utilisation model and (b) interact with variation that arises from the traits of individual pigs. We used a P intake and utilisation model to address these characteristics. Introduction of stochasticity gave rise to a number of methodological challenges - for example, how to generate variation in both feed composition and pigs and account for correlations between ingredients when modelling variation associated with feed mixing efficiency. Introducing variation in feed composition and pig phenotype resulted in moderate decreases in mean digested, retained and excreted $\mathrm{P}$ predicted for a population of pigs and an increase in their associated CV. A lower percentage of pigs in the population were predicted to meet their requirements during the feeding period considered, by comparison with the no-variation scenario. Variation in feed ingredient composition contributed more to performance variation than variation due to mixing efficiency. When variations in both feed composition and pig traits were considered, it was the former rather than the latter that had the dominant influence on variability in pig performance. The developed framework emphasises the consequences of random variability on the predictions of nutrient utilisation models. Such consequences will have a significant impact on decisions about management strategies such as feeding that are subject to variation.

\section{Key words: Co-products: Feed mixing: Phosphorus: Pigs: Populations: Stochastic models}

Apart from a few notable exceptions, most simulation models of nutrient utilisation are deterministic - that is, they deal with the performance of the average animal, offered a diet of a certain composition, while maintained in a relatively constant environment. Some models deal with variation between individual pigs and in aspects of the environment ${ }^{(1-3)}$, but none has dealt with uncertainty in feed composition at a particular point in time or over time. There are several reasons why the latter may be important. Feed ingredients may vary substantially in nutrient composition, due to growing conditions, hybrid or variety differences, planting and harvest dates and storage and feed out conditions ${ }^{(4)}$. In addition variation in feed composition may arise from the feed manufacturing process, such as mixing and processing, including, for example, the drying process in the production of distillers dry grain solubles (DDGS $)^{(5-7)}$. Although several authors have identified such uncertainty in feed composition as a significant contributor to variation in performance ${ }^{(8-11)}$, it is surprising that none has taken it into account in nutrient utilisation models.

In this study, we used a previously published, deterministic model that predicts the digestion, utilisation and excretion of $\mathrm{P}$ by growing and finishing pigs ${ }^{(12,13)}$ to address the challenge of incorporating random variation in system components - namely, pig phenotype and feed composition - and investigate its consequences on the utilisation of this nutrient. We used this model as a case in point on how variation in feed ingredients, inefficiency in mixing and variation in the genetic traits of individual pigs can affect the outputs of a nutritional model, in terms of digested, retained and excreted $\mathrm{P}$.

\section{Methods}

The single animal model of Symeou et al. ${ }^{(12)}$ that predicts intake digestion, utilisation and excretion of $\mathrm{P}$ for growing and finishing pigs was used for this purpose. In brief, the deterministic model represented the limited ability of pig endogenous phytase activity to dephosphorylate phytate as a linear function of dietary $\mathrm{Ca}$. Phytate dephosphorylation in the stomach by exogenous microbial phytase enzymes was expressed by a first-order kinetics relationship. The absorption of non-phytate P (NPP) from the lumen of the small intestine into the blood stream was set at $0 \cdot 8$, and the dephosphorylated phytate from the large intestine was assumed to be indigestible. The net efficiency of using digested $\mathrm{P}$ was set at 0.94 and assumed to be independent of body weight $(\mathrm{BW})^{(14)}$. P requirements for both maintenance and growth were made simple functions of body protein mass, and thus functions of animal genotype. Undigested $\mathrm{P}$ was assumed to be excreted in the faeces in both soluble and insoluble forms. An important

Abbreviations: BW, body weight; DigP, digestible phosphorus; Mphy, microbial phytase activity; NPP, non-phytate phosphorus.

* Corresponding author: I. Kyriazakis, email ilias.kyriazakis@newcastle.ac.uk 
assumption underlying the model was that the relationship between the potential protein $(\mathrm{Pr})$ and $\mathrm{P}$ growth is isometric ${ }^{(15-18)}$. For justification of the values of the model parameters and mathematical relationships, the reader is referred to Symeou et $a l^{(12)}$. The deterministic model has been extensively evaluated $^{(13)}$ and has been found to predict satisfactorily the quantitative pig responses, in terms of mean $\mathrm{P}$ digested, retained and excreted, to treatment changes in $\mathrm{P}$ supply, $\mathrm{Ca}$ and exogenous phytase supplementation.

The main inputs to the deterministic model were as follows: (1) pig phenotype, including initial state, (2) feed composition and (3) feeding plan. The model outputs for a single pig are as follows: (1) average daily gain and food intake (FI), (2) body composition, including $\mathrm{P}$ retained and (3) soluble and insoluble, and thus total, $\mathrm{P}$ excreted. Random variation in the model has been included in the animal-related inputs and described in detail by Symeou et al. ${ }^{(3)}$. In addition, in this study, we introduced random variation in feed ingredient composition, variation in the uniformity of the feed arising from mixing and investigated the interactions of these stochastic introductions with the variation in pig genetic traits.

\section{Introduction of random variation in feed ingredient composition and mixing}

For the purpose of this study, only ingredient variation that contributes to variation in phytate (oP), NPP and Ca feed content as well as plant and microbial phytase activities (PPhy and MPhy) was considered. We appreciate that the description of feed $\mathrm{P}$ as phytate and NPP may be limited, as, for example, it does not take into account the effects of processing on $\mathrm{P}$ availability ${ }^{(9)}$. In principle, the model is flexible to incorporate variation in other ingredient resources, provided that such variation has been measured. The NPP in the feed is a combination of plant NPP (pNPP) and inorganic NPP (iNPP). The dietary Ca also derives from plant $(\mathrm{pCa})$ and inorganic $\mathrm{Ca}$ (iCa) sources. The iCa was sourced from both limestone and inorganic salts - that is, mono and dicalcium phosphate.

Variation in the composition of each feed ingredient into the feed was introduced for $\mathrm{P}$ and $\mathrm{Ca}$, by considering the standard deviation of each ingredient, from the largest publicly available database of composition of feed ingredients ${ }^{(19)}$ (see online Supplementary Appendix Table S1). However, for some feed ingredients, the number of samples used to calculate their mean and standard deviation values is small, and these values should be used with caution, as they may be partly a result of a sampling error. Although the Sauvant $e a{ }^{(19)}$ feed tables provided the PPhy activity (FTU) for all ingredients, they did not provide the associated standard deviations. Therefore, variations of ingredient plant phytase activity were derived from elsewhere ${ }^{(20,21)}$. In addition, variation in MPhy supplementation was derived from the literature $^{(22)}$; an SD of 300 FTU/1000 FTU was assumed to reflect the variation in supplemented MPhy activity.

A stochastic Monte Carlo simulation was used to investigate the effect of ingredient variation. The inputs of the Monte Carlo simulation were as follows: (1) mean and (2) standard deviation, in each investigated chemical component, for each dietary ingredient (oP, pNPP, pCa and PPhy) or supplement (iNPP, iCa and MPhy).
Using the Monte Carlo methodology, 500 feeds for each scenario considered were drawn at random from the above distribution. Once the chemical content of each ingredient $(\mathrm{g} / \mathrm{kg}$ ingredient or FTU/ $\mathrm{kg}$ ingredient) for each feed was established, it was multiplied with the ratio of the ingredient's contribution to the feed. The addition of each chemical content of each ingredient resulted in the $\mathrm{oP}_{\mathrm{i}}, \mathrm{pNPP}_{\mathrm{i}}, \mathrm{iNPP}_{\mathrm{i}}, \mathrm{pCa}_{\mathrm{i}}, \mathrm{iCa}_{\mathrm{i}} \mathrm{g} / \mathrm{kg}$ and $\mathrm{PPhy}_{\mathrm{i}}$ and $\mathrm{MPhy}_{\mathrm{i}}$ contents for each feed.

The goal of feed mixing is to evenly distribute all ingredients and nutrients throughout the entire batch of feed ${ }^{(6)}$. A uniform mixture will supply the animal with a balanced diet, ensuring proper nutrient consumption and maximising performance. A CV of $10 \%$ or less for salt or another minor feed ingredient has been adopted as the industry standard to represent a uniformly mixed feed ${ }^{(5,23)}$. Salt is the most common ingredient used to evaluate mixing efficiency ${ }^{(6)}$ and it usually represents $0.3-0.5 \%$ of 'conventional' feeds. Therefore, in theory, ingredients that make up a significant percentage of the feed (e.g. wheat) will have a much lower CV due to mixing, and this needs to be taken into account when formulating rations.

In order to quantify the later statement, it was first necessary to set the target ingredient composition of the selected feed, assuming perfect mixing. Subsequently, based on this feed, a distribution function was specified, where the probability of occurrence of each ingredient equalled its proportion in the target feed. A repeated random sampling from the distribution that specifies the target feed was carried out, and a random feed was constructed from these samples. When the number of samples increased, the actual composition of the random feed automatically moved closer to that of the feed with perfect mixing - that is, low number of samples demonstrated an inefficient mixing process and a high number an efficient mixing process.

The number of samples needed to achieve the required level of mixing was achieved through an iterative Monte Carlo approach. Monte Carlo simulations with the pig model were carried out, where for each run a separate random feed was constructed. After the simulations, the mean and CV of the proportion of each feed ingredient were specified. The CV of some minor ingredients - for example, limestone - was used as an indicator of the efficiency of mixing. Initially we ran the pig model 500 times, and for each simulation we used a random feed, which remained the same throughout a feeding phase, based on 3000 samples. We found that the simulated $\mathrm{CV}$ of limestone content in these feeds was approximately $20 \%$. We considered this as inefficient mixing. To simulate a better mixing process, we ran the pig model 500 times with 6000 feed samples for each simulation. As a result, we got approximately $10 \%$ simulated CV in limestone content, which is considered an efficient mixing according to industry standards ${ }^{(5,23)}$.

\section{Introduction of variation in pig growth traits and start weight}

The growth parameters considered to vary between the pig phenotypes were protein at maturity $\left(\operatorname{Pr}_{\mathrm{m}}\right)$, lipid:protein ratio at maturity $\left(\operatorname{LPr}_{\mathrm{m}}\right)$ and the scaled maturity rate $\left(B^{*}\right)^{(1-3,24,25)}$. A justification for the choice of these parameters, the lack of correlation between them and why they are able to account for 
both growth rate and body composition in individual pigs is given in the study by Symeou et al. ${ }^{(3)}$.

The mean of $\operatorname{Pr}_{\mathrm{m}}$ were estimated from the study by Knap et al. ${ }^{(26)}$ to be 35 and (SD 4.38$) \mathrm{kg}$. The mean of $B^{*}$ were estimated at 0.0392 and (SD 0.0078$) \mathrm{kg} / \mathrm{d}$, respectively, from the calculations of Brossard et al. ${ }^{(27)}$ for the data of Rivest ${ }^{(28)}$; the details of how this estimate was derived are also given in the study by Symeou et $a l^{(3)}$. Finally, the mean of $\operatorname{LPr}_{\mathrm{m}}$ were derived from Knap and Rauw $^{(29)}$ to be 1.50 and (SD 0.315$) \mathrm{kg} / \mathrm{kg}$, which were in turn adapted from the study by Doeschl-Wilson et al. ${ }^{(30)}$. The initial BW of the pigs $\left(\mathrm{BW}_{0}\right)$ was in accordance with the methodology of Wellock et $a l^{(2)}$, having an average $\mathrm{BW}_{0}$ of $30 \mathrm{~kg}$, and their chemical composition was calculated assuming that the pigs had their ideal composition set by the genotype ${ }^{(31)}$. The values of $B^{*}, \operatorname{Pr}_{\mathrm{m}}$ and $\operatorname{LPr}_{\mathrm{m}}$ were assumed to be uncorrelated and normally distributed $^{(1-3,24,25)}$.

\section{Simulation scenarios considered}

The model was run between 30 and $120 \mathrm{~kg}$ average pig BW. The growth parameters that represent a current genotype were used to derive the requirements for net energy (NE) (MJ), standardized ileal digestible (SID) $(\mathrm{g})$ and digestible $\mathrm{P}(\operatorname{digP})(\mathrm{g} / \mathrm{d})$, in accordance with Symeou et $a l .{ }^{(12)}$. The composition of the feed offered to the pigs changed only once during the simulations at $75 \mathrm{~kg}$ $\mathrm{BW}$, in order to meet the nutrient and energy requirements of the average pig. In all scenarios used, the average digP requirements were at the mid-point BW of each feeding period, which was $52 \mathrm{~kg}$ for the grower period (30-75 kg BW) and $98 \mathrm{~kg} \mathrm{BW}$ for the finisher period $(76-120 \mathrm{~kg}$ ). The NE and Lys feed contents were chosen so that the feed was first limiting in digP during each period under consideration (see Table 1).

\section{Simulations for variation in feed ingredient composition and mixing efficiency}

We first considered random variation in ingredient composition (e.g. as a result of growing conditions, hybrid or variety differences, planting and harvest dates and storage and processing) and subsequently variation resulting from potentially inefficient feed mixing. The effects of these variations were considered on either a 'conventional' feed or a feed based on co-products (Table 1). The 'co-product'-based feed was chosen in order to consider the consequences of higher inherent variation in ingredient composition ${ }^{(19)}$. These feeds were used as a case point to investigate the effect of ingredient variation and/or mixing on $\mathrm{P}$ retention and excretion.

The experimental design addressed by the simulations was a $2 \times 2 \times 3$ factorial design of two feed compositions ('conventional' or 'co-product'-based feeds), variation in ingredient composition (with or without) and variation in mixing (no mixing effect, efficient or inefficient mixing). At this stage, no variation in the pig growth parameters was included. Therefore, 500 Monte Carlo iterations were used to generate each scenario described above.

For the 'conventional' feed scenario, the grower and finisher feeds were formulated on a least-cost formulation (LCF) basis. For each feeding phase, requirements were specified for thirteen nutritional parameters, with the most important being NE $(\mathrm{MJ} / \mathrm{kg})$, crude protein, SID Lys and minerals including total Ca, total $\mathrm{P}$ and $\operatorname{digP}(\mathrm{g} / \mathrm{kg})$. In all, seventeen typical ingredients used in UK feed mills were considered; the Sauvant et $a l^{(19)}$ feed tables were used to determine nutritional composition and digestibility values of these ingredients. Information on ingredient prices for most ingredients was obtained from the Public Ledger ${ }^{(32)}$, with specific information on prices for minerals and amino acids provided by Premier Nutrition.

Table 1. Ingredient and calculated chemical composition of feeds based on conventional and co-product ingredients, offered to growing (30-75 kg body weight (BW)) and finishing (76-120 kg BW) pigs

\begin{tabular}{|c|c|c|c|c|}
\hline & \multicolumn{2}{|c|}{ 'Conventional' feed } & \multicolumn{2}{|c|}{ 'Co-product'-based feed } \\
\hline & Growing & Finishing & Growing & Finishing \\
\hline \multicolumn{5}{|l|}{ Ingredients (\%) } \\
\hline Barley & $16 \cdot 1$ & 37.4 & - & 7.80 \\
\hline Wheat & $50 \cdot 0$ & $40 \cdot 8$ & $37 \cdot 0$ & 33.9 \\
\hline Wheat feed & - & - & 5.00 & $5 \cdot 00$ \\
\hline Wheat DDGS & - & - & $25 \cdot 0$ & $25 \cdot 0$ \\
\hline Soyabean $47 \%$ & $21 \cdot 3$ & 6.35 & $12 \cdot 4$ & $13 \cdot 4$ \\
\hline Rapeseed ext. & 8.00 & 12.5 & - & - \\
\hline Potato protein & - & - & 13.5 & $7 \cdot 30$ \\
\hline Soya oil & $2 \cdot 16$ & 0.500 & 4.06 & 2.00 \\
\hline Limestone & 0.800 & 0.790 & 0.900 & 0.800 \\
\hline Monocalcium phosphate & 0.300 & 0.110 & 0.100 & - \\
\hline Sodium chloride & 0.740 & 0.740 & 0.660 & 0.590 \\
\hline Premix ${ }^{*}$ & 0.650 & 1.40 & 0.940 & 1.52 \\
\hline \multicolumn{5}{|l|}{ Calculated composition $†$} \\
\hline Net energy (MJ/kg) & $10 \cdot 0$ & $9 \cdot 60$ & $10 \cdot 0$ & 9.60 \\
\hline Protein $(\mathrm{g} / \mathrm{kg})$ & 202 & 157 & 223 & 181 \\
\hline Total Lys (g/kg) & $12 \cdot 8$ & $9 \cdot 60$ & $12 \cdot 8$ & $9 \cdot 60$ \\
\hline Total Ca (g/kg) & 6.40 & $6 \cdot 60$ & $6 \cdot 30$ & $6 \cdot 50$ \\
\hline Total P $(\mathrm{g} / \mathrm{kg})$ & 5.50 & $5 \cdot 70$ & 5.50 & 5.50 \\
\hline Digestible P (g/kg) & $3 \cdot 20$ & $2 \cdot 70$ & $3 \cdot 20$ & $2 \cdot 70$ \\
\hline
\end{tabular}

DDGS, distillers' dry grain solubles.

* Provided sufficient quantities of vitamins and micro-minerals.

† Calculated compositions from Sauvant et al. ${ }^{(19)}$ feed tables. 
An Excel solver-based linear optimisation tool was used to formulate separate feeds when optimising for LCF. Using the solver function, the inclusion of all ingredients added to $100 \%$, and the derived feed reached or exceeded the target nutrient values specified at the lowest possible price, without exceeding the specified inclusion limits. The 'co-product'-based feed did not follow a least-cost methodology, because it was forced to contain ingredients with large inherent variation in $\mathrm{P}$ and $\mathrm{Ca}$, irrespective of the cost. Therefore, DDGS and potato protein concentrate were used. This 'co-product' feed formulation had a similar chemical composition with the 'conventional' one (see Table 1).

\section{Simulations for variation in both feed composition and pig growth traits}

The experimental design addressed was a $2 \times 2 \times 3$ factorial design of two feed compositions ('conventional' or 'cOproduct'-based feeds), variation in feed due to mixing process efficiency and ingredient composition (with or without variation in feed composition) and different degrees of variation in pig phenotypic traits (no variation, 'low' and 'normal' variation). The main difference of this experimental design in comparison with the previous one was that phenotypic variation and variation in feed were included for both the 'conventional' and 'co-product'-based feed.

According to the methodology of Pomar et al. ${ }^{(25)}$, we compared populations with different between-animal phenotypic variation. Three populations were generated having 0, 0.5 and 1 times the estimated phenotypic variation of the above reference population. Reducing variation in the growth parameters to 0.5 of the current estimates is consistent with industry desire to increase uniformity among commercial pigs ${ }^{(33)}$. A 500 Monte Carlo iteration was applied for each scenario, having a unique combination of the parameters $\mathrm{BW}_{0}, \mathrm{Pr}_{\mathrm{m}}, \mathrm{LPr}_{\mathrm{m}}$ and $B^{*}$. The populations addressed in the 0.5 and 1 scenarios differed only in the standard deviation of the distribution of the means of the growth parameters.

\section{Simulation outputs}

From the generated simulated populations, which were fed according to the above scenarios, the following outputs were calculated: the population means and standard deviation for total $\mathrm{P}$ digested, excreted and retained per day, and the percentage of the population that had their digP requirements met throughout the BW period $30-120 \mathrm{~kg}$ of the population. Detailed descriptions of the latter calculations can be found in the study by Symeou et al. (3).

\section{Results}

\section{Introduction of variation in feed ingredient composition and mixing efficiency}

We first address the consequences of introducing variation on the resulting feed composition $\mathrm{CV}$ and subsequently on the pig traits. As expected, the introduction of variation due to mixing increased the $\mathrm{CV}$ of the mean content of an ingredient in the resulting feeds (Table 2). The higher the percentage contribution of an ingredient in the feed, the lower its $\mathrm{CV}$ associated with the mean content of the ingredient in the resulting simulations, when mixing efficiency was introduced (see Table 2). The 'co product'-based feeds had a higher CV associated with the mean content of each ingredient than the 'conventional' feeds. In some cases, introduction of inefficient mixing in a co-product-based feed increased the CV associated with the mean content of a minor ingredient dramatically - for example, upto approximately $60 \%$ for monocalcium phosphate. This introduced enormous variation in the resulting feed compositions, and as will be seen below it has important consequences on system outputs.

Introducing variation in ingredient composition resulted in a moderate decrease in the mean digP input, $\mathrm{P}$ retained and $\mathrm{P}$ excreted by the population of pigs offered 'co-product'-based feeds (see Table 3 ). On the other hand, there were no substantial changes $(<0.5 \%$ reductions $)$ in these outputs when the population

Table 2. The effect of feed mixing (efficient and inefficient mixing) on the mean content in each ingredient of the resulting feed* (Mean values and coefficients of variations)

\begin{tabular}{|c|c|c|c|c|c|c|c|c|c|c|c|c|c|c|c|c|}
\hline \multirow[b]{4}{*}{ Ingredients (\%) } & \multicolumn{8}{|c|}{ Efficient mixing } & \multicolumn{8}{|c|}{ Inefficient mixing } \\
\hline & \multicolumn{4}{|c|}{ 'Conventional' feed } & \multicolumn{4}{|c|}{ 'Co-product' feed } & \multicolumn{4}{|c|}{ 'Conventional' feed } & \multicolumn{4}{|c|}{ 'Co-product' diet feed } \\
\hline & \multicolumn{2}{|c|}{ Growing } & \multicolumn{2}{|c|}{ Finishing } & \multicolumn{2}{|c|}{ Growing } & \multicolumn{2}{|c|}{ Finishing } & \multicolumn{2}{|c|}{ Growing } & \multicolumn{2}{|c|}{ Finishing } & \multicolumn{2}{|c|}{ Growing } & \multicolumn{2}{|c|}{ Finishing } \\
\hline & Mean & CV & Mean & CV & Mean & CV & Mean & CV & Mean & CV & Mean & CV & Mean & $\mathrm{CV}$ & Mean & CV \\
\hline Barley & $16 \cdot 1$ & $2 \cdot 19$ & 37.4 & 1.20 & - & & 7.78 & 3.33 & $16 \cdot 1$ & 4.25 & 37.4 & 2.48 & - & - & 7.82 & 6.42 \\
\hline Wheat & 50.0 & 0.970 & $40 \cdot 8$ & 1.22 & $37 \cdot 0$ & 1.29 & 34.0 & 1.31 & 49.9 & 1.46 & $40 \cdot 8$ & 2.34 & 37.0 & 2.45 & 33.9 & 2.50 \\
\hline Wheat feed & - & - & - & - & 5.03 & 4.48 & 4.97 & 4.40 & - & - & - & - & 4.98 & $8 \cdot 21$ & 4.99 & 7.89 \\
\hline Wheat DDGS & - & - & - & - & $25 \cdot 1$ & 1.76 & $25 \cdot 0$ & 1.75 & - & - & - & - & $25 \cdot 0$ & 3.08 & $25 \cdot 0$ & $3 \cdot 11$ \\
\hline Soyabean $47 \%$ & $21 \cdot 3$ & 1.83 & 6.33 & 3.67 & $12 \cdot 4$ & 2.63 & $13 \cdot 4$ & $2 \cdot 50$ & $21 \cdot 3$ & 3.71 & $6 \cdot 35$ & $7 \cdot 37$ & $12 \cdot 4$ & 4.78 & $13 \cdot 4$ & 4.67 \\
\hline Rapeseed ext. & 8.02 & 3.58 & 12.5 & 4.27 & - & - & - & - & 7.98 & 6.35 & 12.5 & 4.97 & - & - & - & - \\
\hline Potato protein & - & - & - & - & 13.5 & 2.44 & 7.31 & 3.52 & - & - & - & - & 13.5 & 4.51 & 7.29 & 6.44 \\
\hline Limestone & 0.800 & 11.2 & 0.790 & $11 \cdot 1$ & 0.900 & 10.5 & 0.800 & 10.5 & 0.800 & $19 \cdot 0$ & 0.790 & $19 \cdot 4$ & 0.900 & $19 \cdot 1$ & 0.810 & 19.6 \\
\hline MCP & 0.300 & 18.5 & 0.110 & $28 \cdot 8$ & $0 \cdot 100$ & 31.9 & - & - & 0.300 & 33.5 & 0.110 & 55.4 & 0.100 & 58.8 & - & - \\
\hline Othert & 3.54 & $5 \cdot 10$ & 2.09 & 6.71 & 6.09 & 4.00 & $6 \cdot 79$ & 3.87 & 3.56 & 9.22 & $2 \cdot 12$ & 12.5 & $6 \cdot 12$ & 7.43 & $6 \cdot 81$ & $6 \cdot 81$ \\
\hline
\end{tabular}

DDGS, distillers' dry grain solubles; MCP, monocalcium phosphate.

* The feeds were based either on 'conventional' or on co-product ingredients and were offered to growing (30-75 kg body weight (BW)) and finishing (76-120 kg BW) pigs; the means are based on 500 Monte Carlo simulations.

† Premix, soya oil and sodium chloride. 
Table 3. The effect of variation in ingredient composition (with (yes) or without (no)) and mixing (no mixing (NM), efficient (E) or inefficient (I) mixing) of a 'conventional' and a 'co-product'-based feed on the means of phosphorus digested, excreted and retained* (Mean values and coefficients of variations)

\begin{tabular}{|c|c|c|c|c|c|c|c|c|c|c|c|c|c|}
\hline & \multirow[b]{2}{*}{ Treatments } & \multicolumn{4}{|c|}{ P digested $(\mathrm{g} / \mathrm{d})$} & \multicolumn{4}{|c|}{$P$ retained $(g / d)$} & \multicolumn{4}{|c|}{$P$ excreted $(g / d)$} \\
\hline & & \multicolumn{2}{|c|}{ 'Conventional' feed } & \multicolumn{2}{|c|}{ 'Co-product' feed } & \multicolumn{2}{|c|}{ 'Conventional' feed } & \multicolumn{2}{|c|}{ 'Co-product' feed } & \multicolumn{2}{|c|}{ 'Conventional' feed } & \multicolumn{2}{|c|}{ 'Co-product' feed } \\
\hline Mixing & $\begin{array}{l}\text { Variation in ingredient } \\
\text { composition }\end{array}$ & Mean & CV (\%) & Mean & CV (\%) & Mean & $\mathrm{CV}(\%)$ & Mean & CV (\%) & Mean & CV (\%) & Mean & CV $(\%)$ \\
\hline NM & No & 7.07 & 0 & 7.07 & 0 & 5.82 & 0 & 5.83 & 0 & 7.44 & 0 & 7.45 & 0 \\
\hline NM & Yes & 7.06 & 4.20 & 6.80 & 9.71 & 5.83 & 2.44 & 5.59 & $7 \cdot 27$ & $7 \cdot 46$ & $5 \cdot 61$ & $7 \cdot 20$ & 9.04 \\
\hline E & No & 6.98 & 3.13 & 6.87 & 2.08 & 5.78 & 2.05 & 5.73 & 1.58 & 7.35 & 2.80 & $7 \cdot 19$ & 2.05 \\
\hline $\mathrm{E}$ & Yes & 6.97 & $5 \cdot 36$ & $6 \cdot 86$ & $10 \cdot 1$ & 5.75 & 3.61 & $5 \cdot 62$ & $7 \cdot 36$ & $7 \cdot 37$ & $6 \cdot 28$ & $7 \cdot 29$ & $10 \cdot 3$ \\
\hline I & No & $6 \cdot 90$ & $6 \cdot 23$ & 6.79 & 4.52 & $5 \cdot 71$ & 4.63 & $5 \cdot 67$ & 3.88 & $7 \cdot 26$ & 6.08 & $7 \cdot 26$ & $6 \cdot 37$ \\
\hline I & Yes & $6 \cdot 89$ & 7.73 & $6 \cdot 80$ & $11 \cdot 1$ & $5 \cdot 68$ & 5.55 & 5.57 & $8 \cdot 27$ & $7 \cdot 28$ & 8.04 & $7 \cdot 37$ & $11 \cdot 0$ \\
\hline
\end{tabular}

* The results are the outcomes of 500 simulations.

of pigs was offered 'conventional' feeds that included variation in ingredient composition. Introducing variation in ingredient composition resulted in the expected increase in the CV of the model outputs by the population of pigs offered either the 'conventional' or 'co-product'-based feeds, with the 'co-product'based feeds leading to approximately twice as high $\mathrm{CV}$ than the 'conventional' feeds. The reason for the lower P digested, retained and excreted by pigs on the co-product-based feeds in comparison with the 'conventional' feeds was due to the higher variation in the supply of $\mathrm{P}$, Ca and phytase activity to the pigs. Owing to the variation introduced by ingredient composition, a larger number of pigs met their digP requirements at the earlier stages of feeding the co-product-based feeds, because more $\mathrm{P}$ was supplied than planned. The converse was the case during the latter stages of the feeding phase, where a number of pigs were under-supplied with $\mathrm{P}$ on these feeds. As more $\mathrm{P}(\mathrm{g} / \mathrm{d})$ is required as pigs grow $^{(12,34)}$ that is, at the latter stages of each feeding phase - overall less $\mathrm{P}$ was supplied and retained on the co-product-based feeds than the conventional feeds.

Variation in mixing efficiency also slightly reduced the average digP intake, $\mathrm{P}$ retained and $\mathrm{P}$ excreted by the population of pigs, offered either the conventional or co-product-based feeds and increased their associated CV. The decrease in the model outputs and the increase in their associated CV were twice as much when mixing was less efficient than when it was efficient. The reasons for the reduced average dig $\mathrm{P}$ intake, retained and excreted when mixing variation was introduced are identical to those detailed above, when the consequences due to the introduction of variation in ingredient content were accounted for - for example, there was a $4.1 \%$ decrease in the $\mathrm{P}$ retained when the population was given a 'co-product'-based feed that included variation in ingredient composition and $2.7 \%$ reduction in the same output when this arose from simulations that included inefficient mixing. The reduction in the $\mathrm{P}$ retained was $4.5 \%$ when both variation in ingredient composition and inefficient mixing were included in the same feed.

In all cases, an inefficient mixing process slightly increased the number of pigs that met their requirements during the first half of each feeding phase (Fig. 1). During the second half of each feeding phase, it was the efficient mixing process that greatly increased the number of pigs that met their requirements. Approximately $15 \%$ did not meet their digP requirements by the end of each of the
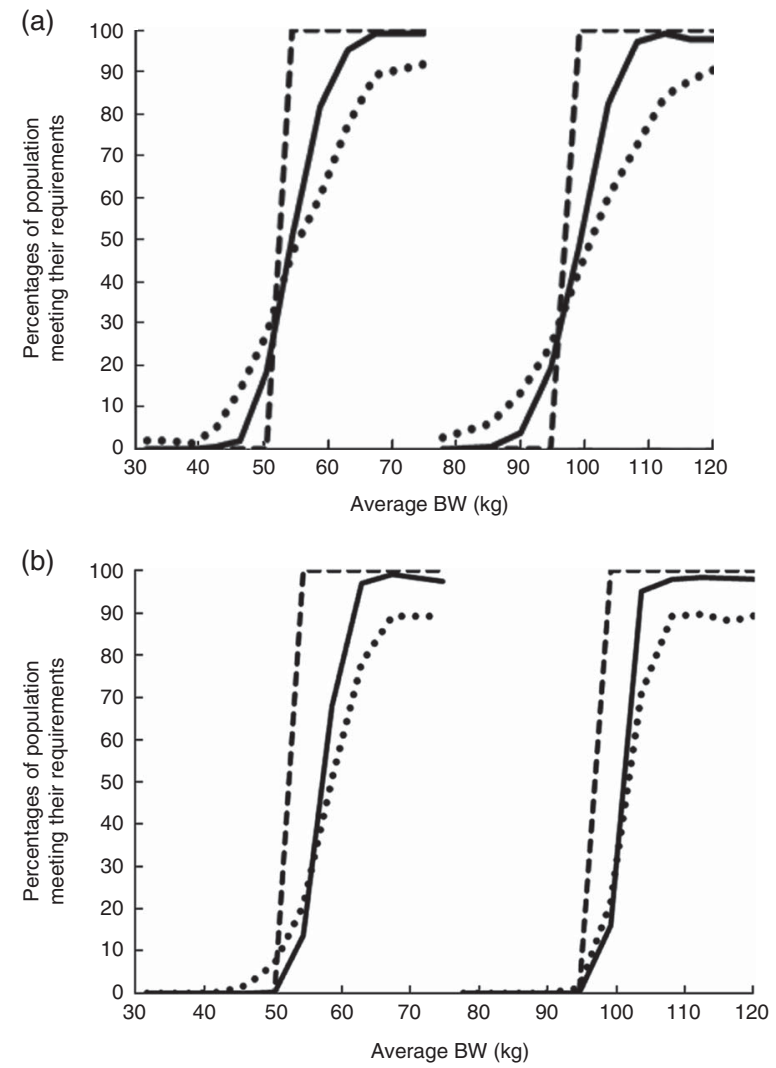

Fig. 1. The percentage of the population of pigs that met their digestible phosphorus requirements over the average body weight (BW) range 30-120 kg, while being fed (a) 'conventional' and (b) 'co-product'-based feed, either with no variation (_- or with variation due to an efficient ( - ) or an inefficient mixing process (.............). All pigs were assumed to be identical in the genetic parameters that defined their growth characteristics.

feeding phase, when they were offered feeds that resulted from an inefficient mixing process (see Fig. 1).

The addition of variation due to the mixing process to the ingredient variation increased further the percentage of pigs that met their requirements during the first half of each phase (Fig. 2(a) and (b)), in comparison with when there was only variation due to the mixing process (Fig. 1(a) and (b)), and vice versa during the second half of each phase. This was the case 
when the feeds offered to the pigs were based on conventional ingredients only; the lowest percentage of pigs meeting their digP requirements was seen when the feeds were based on co-products and when pigs were offered feeds that included variation due to both ingredients and mixing process. An appreciable percentage of pigs (approximately 15\%) did not meet their digP requirements by the end of each of the feeding
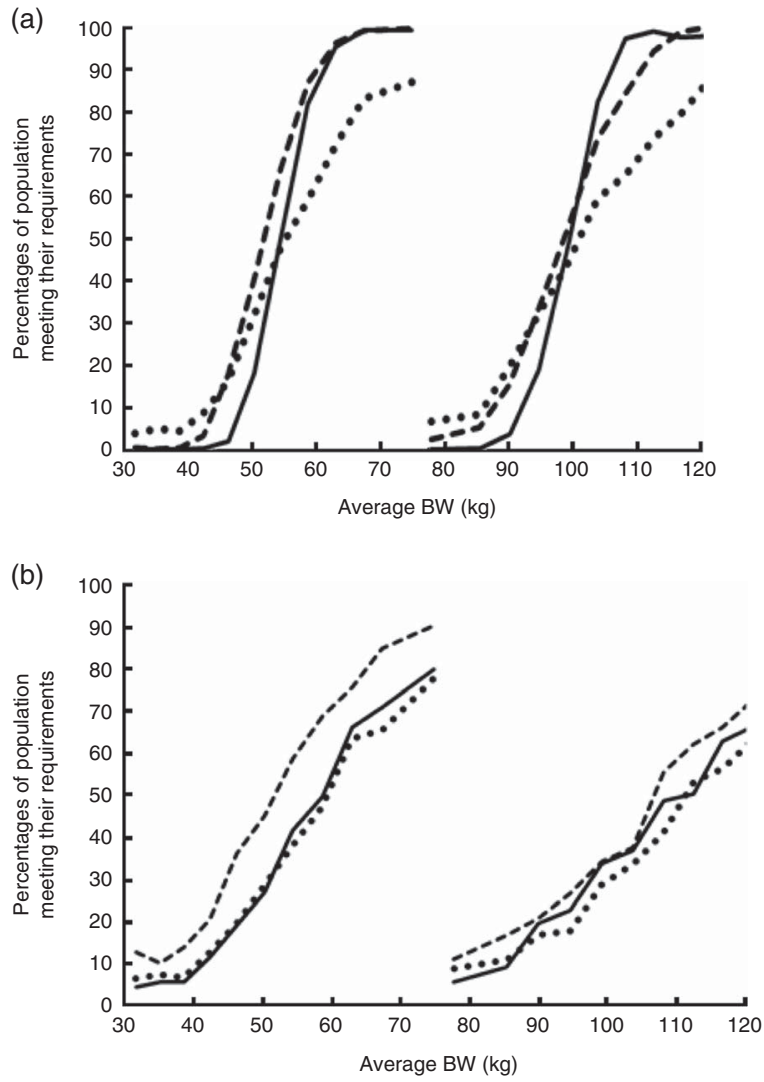

Fig. 2. The percentage of the population of pigs that met their digestible phosphorus requirements over the average body weight (BW) range 30-120 kg, while being fed (a) 'conventional' feed and (b) 'co-product'-based feed, either with variation in ingredient composition $(--)$ or with variation in ingredient composition and variation due to the mixing process (efficient $(\longrightarrow)$ or inefficient mixing process (.............)). All pigs were assumed to be identical in the genetic parameters that defined their growth characteristics. phase when the feeds included variation due to both ingredients and inefficient mixing, for 'conventional' diets. Only 87 and $60 \%$ of the pigs managed to achieve their digP requirements during the finisher period in these cases for conventional and co-product-based feeds, respectively, when the mixing process was inefficient (Fig. 2).

\section{Introduction of variation in feed ingredient composition, mixing efficiency and pig growth traits}

There was a slight decrease in the average P digested, retained and excreted as the variation among the growth parameters of the pigs increased; this was associated with an expected increase in the associated CV (see Table 4). The differences between no variation and 'low' variation in the above outputs were within the $0.5 \%$ sE limits resulting from the Monte Carlo simulations. However, the decreases in the values of the outputs reflected the fact that, as phenotype variation increased, a larger number of pigs were unable to meet their digP requirements, which targeted the 'average' pig for a longer period of time, and this adversely affected $\mathrm{P}$ retention and ultimately their growth. This was due to the fact that in this study protein growth was assumed to be directly proportional to $\mathrm{P}$ retention even under conditions of $\mathrm{P}$ deficit.

In the presence of variation due to feed, the average $\mathrm{P}$ digested, retained and excreted decreased further as the variation among the growth parameters of the pigs increased. The above decreases were higher in the 'co-product'-based as opposed to the 'conventional' feeds - for example, the realistic scenario that included variation due to the feed and 'normal' genotype variation resulted in 4.0 and $7.2 \%$ less $\mathrm{P}$ retained in comparison with the control scenario with no variation for the 'conventional' and 'co-product'-based feeds, respectively.

Increasing the phenotypic variation in the pig population resulted in a higher percentage of pigs meeting their requirements at the earlier stages, but a lower percentage of pigs meeting their $\operatorname{dig} \mathrm{P}$ requirements at the latter stages of each of the growing and finishing phases; overall, fewer pigs in the population reached their requirements throughout the feeding phase (see Fig. 3). In all, 95 and $82 \%$ of the pigs met their digP requirements during the finisher period, when the variation within the population was

Table 4. The effect of variation in ingredient composition and mixing (with (yes) or without variation (no)) of a 'conventional' and a 'co-product'-based feed, and of different degrees of variation in pig genetic variables (no variation, 'low' and 'normal' variation), on the means of phosphorus digested, excreted and retained" (Mean values and coefficients of variations)

\begin{tabular}{|c|c|c|c|c|c|c|c|c|c|c|c|c|c|}
\hline \multirow{2}{*}{\multicolumn{2}{|c|}{ Treatments }} & \multicolumn{4}{|c|}{$P$ digested $(g / d)$} & \multicolumn{4}{|c|}{$P$ retained $(g / d)$} & \multicolumn{4}{|c|}{ P excreted $(g / d)$} \\
\hline & & \multicolumn{2}{|c|}{$\begin{array}{l}\text { 'Conventional' } \\
\text { feed }\end{array}$} & \multicolumn{2}{|c|}{$\begin{array}{l}\text { 'Co-product' } \\
\text { feed }\end{array}$} & \multicolumn{2}{|c|}{$\begin{array}{l}\text { 'Conventional' } \\
\text { feed }\end{array}$} & \multicolumn{2}{|c|}{$\begin{array}{l}\text { 'Co-product' } \\
\text { feed }\end{array}$} & \multicolumn{2}{|c|}{$\begin{array}{l}\text { 'Conventional' } \\
\text { feed }\end{array}$} & \multicolumn{2}{|c|}{$\begin{array}{l}\text { 'Co-product' } \\
\text { feed }\end{array}$} \\
\hline $\begin{array}{l}\text { Genotype } \\
\text { variation }\end{array}$ & $\begin{array}{l}\text { Variation in ingredient composition } \\
\text { and efficient mixer }\end{array}$ & Mean & CV (\%) & Mean & CV (\%) & Mean & CV (\%) & Mean & CV (\%) & Mean & CV (\%) & Mean & $\mathrm{CV}(\%)$ \\
\hline No & No & 7.07 & 0 & 7.07 & 0 & $5 \cdot 82$ & 0 & $5 \cdot 83$ & 0 & $7 \cdot 44$ & 0 & $7 \cdot 45$ & 0 \\
\hline No & Yes & 6.97 & $5 \cdot 36$ & $6 \cdot 86$ & $10 \cdot 1$ & $5 \cdot 75$ & 3.61 & $5 \cdot 62$ & $7 \cdot 37$ & $7 \cdot 37$ & $6 \cdot 28$ & $7 \cdot 29$ & $10 \cdot 3$ \\
\hline Low & No & 7.07 & $10 \cdot 9$ & 7.07 & $10 \cdot 9$ & $5 \cdot 82$ & $10 \cdot 5$ & $5 \cdot 79$ & $10 \cdot 5$ & $7 \cdot 47$ & $11 \cdot 8$ & 7.49 & $11 \cdot 9$ \\
\hline Low & Yes & 6.98 & $12 \cdot 1$ & $6 \cdot 74$ & $15 \cdot 0$ & $5 \cdot 72$ & $11 \cdot 2$ & 5.54 & 13.5 & $7 \cdot 39$ & $13 \cdot 2$ & $7 \cdot 14$ & $16 \cdot 3$ \\
\hline Normal & No & 7.00 & $21 \cdot 8$ & 6.98 & $22 \cdot 1$ & 5.67 & $21 \cdot 2$ & 5.65 & $21 \cdot 4$ & $7 \cdot 45$ & $23 \cdot 3$ & $7 \cdot 42$ & $23 \cdot 8$ \\
\hline Normal & Yes & $6 \cdot 90$ & $22 \cdot 6$ & $6 \cdot 68$ & $24 \cdot 5$ & 5.59 & 21.6 & 5.41 & $23 \cdot 1$ & $7 \cdot 39$ & $24 \cdot 1$ & $7 \cdot 16$ & $26 \cdot 3$ \\
\hline
\end{tabular}

* The results are the outcomes of 500 simulations. 

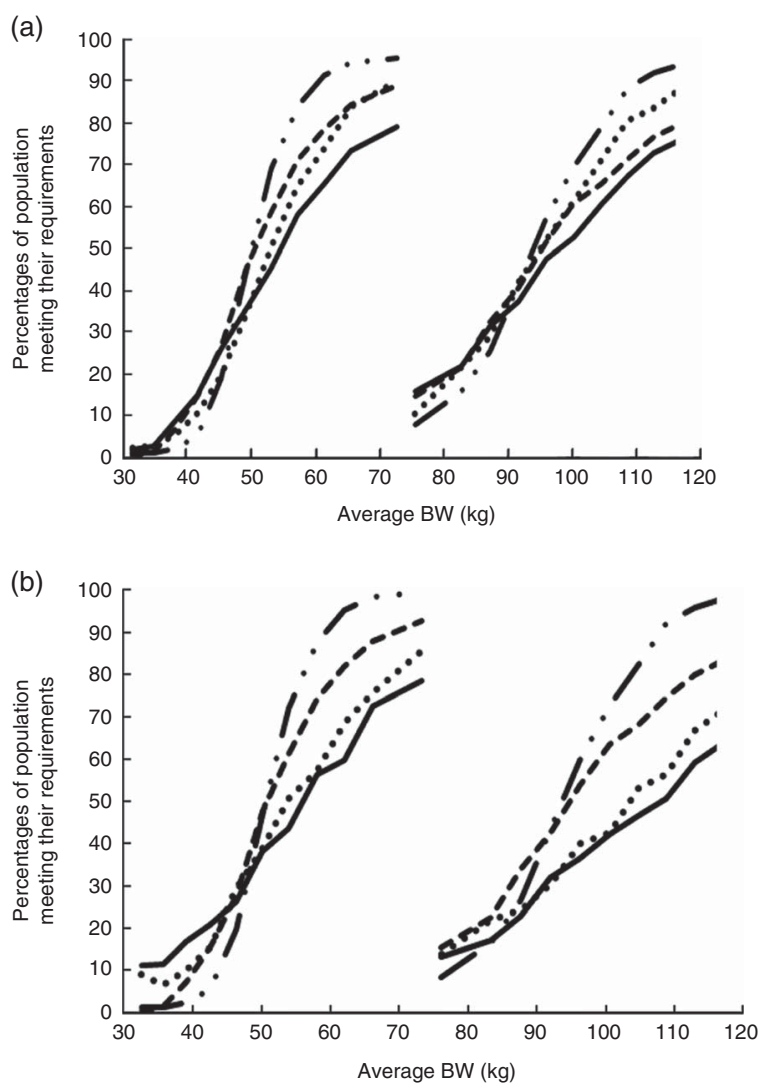

Fig. 3. The percentage of the population of 500 pigs that met their digestible phosphorus requirements over the average body weight (BW) range 30-120 kg, while being fed (a) 'conventional' feed and (b) 'co-product'-based feed. The pigs differed in the variation of their genetic parameters (low or normal variation) and were given access to feeds that included variation in composition due to ingredient variation and mixing (with variation or no variation). The four combinations were as follows: (1) pigs with low genetic variation given access to a feed with no variation (_ ...........); (2) pigs with low variation given access to a feed with variation (............); (3) pigs with normal genetic variation given access to a feed with no variation ( $-\ldots)$; and (4) pigs with normal variation given access to a feed with variation (-).

'low' and 'normal', respectively. The combination of both variation in the feed (due to ingredient composition and mixing) and phenotypic variation resulted in an even lower percentage of the population meeting their digP requirements. This was especially the case when a 'co-product'-based feed was used - for example, the realistic scenario that included variation due to the feed and 'normal' phenotypic variation resulted in 79 and $63 \%$ of the pigs meeting their digP requirements during the finisher period, on the 'conventional' and 'co-product'-based feeds, respectively. This was the outcome of having several pigs with digP requirements well above those of the 'average' pig, which were given access to feeds of low $\mathrm{P}$ content due to variation in ingredient composition and inefficient feed mixing.

\section{Discussion}

The objective of this study was to develop a methodology that would enable the investigation of how (a) variation in feed composition arising from variability in feed ingredient nutrient (P) content and mixing would affect the outputs of a nutrient utilisation simulation model, and (b) how such variations would interact with the variability that arises from the growth traits of individual pigs within a population. We used a $\mathrm{P}$ intake and utilisation simulation model as a case in point, because this was the most complete model of its kind at our disposal, and because the model already included variation in the characteristics of the pigs ${ }^{(3)}$. As far as we know, this is the first attempt to introduce variation in feeding environment in a pig model, although this has been considered previously for dairy cattle ${ }^{(11)}$. The simulations show that the effects of such variation can be profound on model outputs, such as individual pig performance, the variation between individuals within a cohort of pigs and the number of pigs that are either overfed or underfed P. Although this study investigated the consequences of sources of variation on $\mathrm{P}$ digestion, retention and excretion, we expect that the same principles would apply when dealing with the fate of any other nutrient whose intake and utilisation can be subject to similar variation.

Applying the model to account for variation in nutrient intake and utilisation has given rise to a number of methodological challenges - namely, how to generate the variation in both feed composition and pigs, and how to account for correlations between ingredients when modelling the variation associated with mixing efficiency. When modelling the variation associated with the latter, the variation of the feed ingredients follows conditional probabilities - that is, the probability of the proportion of one ingredient in the feed is dependent on the proportion of other ingredients. For complex feed compositions, it is difficult to formulate probability functions to describe these interactions, and therefore we developed a Monte Carlo sampling method, which automatically generates sample feeds with realistic proportions of each ingredient. When introducing variations in ingredient composition, only variation of feed ingredients in $\mathrm{P}, \mathrm{Ca}$ and microbial and plant phytase activities was considered in this study. Clearly, feed ingredients differ in other nutrient resource contents such as energy or amino acid contents. Provided that such a variation is known and included in the input data, the model will automatically take it into account in its simulations. The feed manufacturing industry recognises the potential consequences of variation associated with feed ingredient composition ${ }^{(35)}$ and tries to account for this in various ways in their feed matrices ${ }^{(19)}$. Nevertheless, there are some ingredients that are associated with high inherent variability, such as the co-products DDGS and potato protein $^{(10,36)}$, and this may lead to the results generated in this study: feeding on co-product-based feeds led consistency to higher variation in the performance of pigs, which were assumed to be 'identical' in their growth characteristics. The outcome of the introduction of variation was that a small number of pigs were over-supplied with $\mathrm{P}$ at the early stages and a substantial number of pigs were under-supplied with $\mathrm{P}$ at the latter stages of the feeding phase. Feeding the co-product-based feed exaggerated the latter, and as a consequence a substantial number of pigs failed to meet their digP requirements, even by the end of the feeding phase, and thus they under-performed. The model assumes that when animals do not meet their $\mathrm{P}$ requirements, then their performance would be penalised. However, there are 
suggestions that under certain nutritional conditions this relationship between $\mathrm{P}$ and protein may not be valid. The National Research Council (NRC) ${ }^{(37)}$, for example, suggested that pig can be fed diets with $\mathrm{P}$ contents approximately $10 \%$ below the P requirements without any 'negative' consequences on pig daily gain. If this is the case, then the model would have overestimated some of the consequences of the variation in feed composition on the performance investigated in this study.

Even when the variation associated with the nutrient content of feed ingredients is accounted for, variation in feed composition can arise from the efficiency of the mixing process. There are several factors that can affect this; they include mixing time (insufficient or protracted mixing times can lead to ingredient segregation), feed mixer maintenance, over-filled mixer due to the bulkiness of some ingredient(s), etc. ${ }^{(38-40)}$. We used Monte Carlo iterations to investigate the consequences of two mixing efficiencies: one that resulted in $10 \% \mathrm{CV}$ in the content of limestone in the feed, which is the industry-accepted level, resulting from efficient mixing ${ }^{(41)}$, and another that resulted in $20 \% \mathrm{CV}$, which is within the realistic bounds of mixing of pig feeds ${ }^{(23)}$. Again the effects of the mixing efficiency on the model outputs were higher in the coproduct-based feeds, mainly because they contained a larger number of ingredients. A larger number of ingredients meant a smaller contribution of each ingredient to each feed, therefore resulting in greater cumulative uncertainty in the resulting feeds, and thus their outcomes. Future extension of this model could include prediction of this mixing effect on the $\mathrm{P}$ excretion from a population, by using scenarios such as (1) different types of feed mixers (i.e. vertical, horizontal and drum), (2) different mixing times and (3) the effect of premixing low inclusion ingredients (e.g. monocalcium phosphate), rather than empirically investigating the mixing effect.

The consequences of mixing efficiency on the performance of a population are slightly at odds with what has been suggested in the literature. Groesbeck et al. ${ }^{(6)}$ and Traylor et $a l .{ }^{(5)}$ have concluded that a CV of salt of upto 12 and $20 \%$ in pig feeds, respectively, is adequate for maximum growth performance of pigs. This discrepancy may be due to the fact that the model currently overestimates the effect of P deficiency on the reduction of protein growth, as discussed above. As a result of variation due to the mixing efficiency, the feed could vary in its energy and protein contents, as well as $\mathrm{P}$, if, for example, more soya was used than intended at the expense of wheat. This would have effects on the FI of the pigs, and thus their performance. Again this effect needs to be taken into account for the further development of the model.

Owing to the assumptions made by the model in the scenarios investigated, variation in feed ingredient composition for the 'co-product'-based feed contributed more to performance variation than variation due to the mixing efficiency. This in part justifies the approach taken by feed manufacturers to use a higher number of feed ingredients in order to avoid or reduce the effects of variation arising from over-reliance on a few ingredients with large inherent variation. This reduction will only in part be offset by the potential contribution of the several ingredients to the mixing inefficiency.

The study investigated the interactions between variation in $\mathrm{P}$ dynamics due to variability in the feed and due to variability in the pig. The most striking outcome of the simulation was the fact that in the presence of variation in the feed composition the number of pigs that met their digP requirements was similar, irrespective of whether the variability in the pig growth parameters was high (normal) or low. This was especially the case when pigs were fed a co-product-based feed, where the percentage of pigs that met their requirements at the end of the finisher period was approximately $60 \%$. In other words, when pigs were simulated under conditions likely to be encountered in commercial environments, it was variation about the 'co-product'-based feed composition, rather than pig characteristics, that proved to have the dominant influence on variability in pig performance. At present, there is an increased interest in how to deal with variability within a batch of pigs ${ }^{(42,43)}$, due to the financial consequences associated with it, and feeding strategies to overcome this are being developed ${ }^{(44,45)}$. The model developed in this study was able to account for the interactions between feeding strategies and variability within a batch of pigs. It can be envisaged that such interactions may arise if the smaller pigs are given access to a different feeding regimen associated with these variations.

\section{Conclusion}

We developed a methodology able to account for variation in $\mathrm{P}$ dynamics due to variation in feed composition and pig genotype. The methodology has pointed towards some issues that need to be addressed to increase model accuracy and utility. Such issues include the need to take into account the inherent variability in the ingredient energy and amino acid concentrations, as well as the development of a 'bone growth compartment', which can be utilised at times of dietary P deficiencies. The methodology has demonstrated the potential of variation to affect the predictions of a nutrient intake and utilisation model. The developed framework can be used to investigate the consequences for pig performance of variation with regard to several components of the system - namely, the pig, its feed and its environment. Such consequences are likely to have significant impact on decisions about how to feed pig populations that are subject to variation.

\section{Acknowledgements}

This project was sponsored by British Pig Executive (Now Agricultural and Horticultural Development Board - Pork) in the form of a postgraduate studentship to V. S.

This paper derives from the doctoral thesis of V. S. under the supervision of I. K. and I. L. designed the experimental approach, V. S. carried out the model simulations and all three authors contributed equally to the interpretation of the outcomes and the reporting of the paper.

The authors declare that there are no conflicts of interest.

\section{Supplementary material}

For supplementary material/s referred to in this article, please visit http://dx.doi.org/doi:10.1017/S0007114515004523 


\section{References}

1. Ferguson NS, Gous RM \& Emmans GC (1997) Predicting the effects of animal variation on growth and feed intake in growing pigs using simulation modelling. Anim Sci 64, 513-522.

2. Wellock IJ, Emmans GC \& Kyriazakis I (2004) Modeling the effects of stressors on the performance of populations of pigs. J Anim Sci 82, 2442-2450.

3. Symeou V, Leinonen I \& Kyriazakis I (2015) Quantifying the consequences of nutritional strategies aimed at decreasing phosphorus excretion from pig populations: a modelling approach. Animal (epublication ahead of print version 6 November 2015).

4. Kim CJ, Mullan BP, Selle PH, et al. (2002) Level of total phosphorus, phytate-phosphorus, and phytase activity in three varieties of Western Australian wheats in response to growing region, growing season, and storage. Aust J Agric Res 53, 1361-1366.

5. Traylor SL, Hancock JD, Behnke KC, et al. (1994) Uniformity of mixed diets affects growth performance in nursery and finishing pigs. J Anim Sci 72, Suppl. 2, 59 (Abstract).

6. Groesbeck CN, Goodband RD, Tokach MD, et al. (2007) Diet mixing time affects nursery pig performance. J Anim Sci $\mathbf{8 5}$, 1793-1798.

7. Pedersen C, Boersma MG \& Stein HH (2007) Digestibility of energy and phosphorus in ten samples of distillers dried grains with solubles fed to growing pigs. J Anim Sci 85, 1168-1176.

8. Hendriks WH, Butts CA, Thomas DV, et al. (2002) Nutritional quality and variation of meat and bone meal. Asian-Aust J Anim Sci 15, 1507-1516.

9. Spiehs MJ, Whitney MH \& Shurson GC (2002) Nutrient data base for distillers dried grains with solubles produced from new generation ethanol plants in Minnesota and South Dakota. J Anim Sci 80, 2639-2645.

10. Stein HH, Connot SP \& Pedersen C (2009) Energy and nutrient digestibility in four sources of distillers dried grains with solubles produced from corn grown within a narrow geographical area and fed to growing pigs. Asian-Aust J Anim Sci 22, 1016-1025.

11. Weiss W, Shoemaker PD, McBeth LR, et al. (2012) Within farm variation in nutrient composition of feeds. In Proceedings of the Tri-State Dairy Nutrition Conference, Ft. Wayne, IN, pp. 103-114. Columbus, OH: The Ohio State University.

12. Symeou V, Leinonen I \& Kyriazakis I (2014) Modelling phosphorus intake, digestion, retention and excretion in growing and finishing pigs: model description. Animal 8, $1612-1621$.

13. Symeou V, Leinonen I \& Kyriazakis I (2014) Modelling phosphorus intake, digestion, retention and excretion in growing and finishing pigs: model evaluation. Animal 8, 1622-1631.

14. Kyriazakis I (2011) Opportunities to improve feed efficiency in pigs and poultry through breeding. Animal 5, 821-832

15. Rymarz A, Fandrejewski H \& Kielanowski J (1982) Content and retention of calcium, phosphorus, potassium and sodium in the bodies of growing gilts. Livest Prod Sci 9, 399-407.

16. Jongbloed AW (1987) Phosphorus in the feeding of pigs. Effect of diet on the absorption of phosphorus by growing pigs. PhD Thesis, University of Wageningen.

17. Hendriks WH \& Moughan JP (1993) Whole-body mineral composition of entire male and female pigs depositing protein at maximal rate. Livest Prod Sci 33, 161-170.

18. Mahan DC \& Shields RG (1998) Essential and nonessential amino acid composition of pigs from birth to 145 kilograms of body weight, and comparison to other studies. .J Anim Sci 76, 513-521.

19. Sauvant D, Perez JM \& Tran G (editors) (2004) Tables of Composition and Nutritional Value of Feed Materials: Pigs,
Poultry, Cattle, Sheep, Goats, Rabbits, Horses and Fish. Wageningen: Wageningen Academic Publishers.

20. Viveros A, Centeno C, Brenes A, et al. (2000) Phytase and acid phosphatase activities in plant feedstuffs. J Agric Food Chem 48, 4009-4013.

21. Steiner T, Mosenthin R, Zimmermann B, et al. (2007) Distribution of phytase activity, total phosphorus and phytate phosphorus in legume seeds, cereals and cereal by-products as influenced by harvest year and cultivar. Anim Feed Sci Tech 133, 320-334.

22. Akinmusire AS \& Adeola O (2009) True digestibility of phosphorus in canola and soybean meals for growing pigs: influence of microbial phytase. J Anim Sci 87, 977-983.

23. Herrman T \& Behnke K (1994) Testing mixer performance. Kansas State University Agriculture Experiment Station and Cooperative Extension Service, MF-1172 Feed Manufacturing. http://www.ksre.ksu.edu/bookstore/pubs/MF1172.pdf (accessed March 2013).

24. Knap PW (2000) Stochastic simulation of growth in pigs: relations between body composition and maintenance requirements as mediated through protein turn-over and thermoregulation. Anim Sci 71, 11-30.

25. Pomar C, Kyriazakis I, Emmans GC, et al. (2003) Modeling stochasticity: dealing with populations rather than individual pigs. J Anim Sci 81, E178-E186.

26. Knap PW, Roehe R, Kolstad K, et al. (2003) Characterisation of pig genotypes for growth modelling. J Anim Sci 80, E187-E195.

27. Brossard L, Dourmad JY, Rivest J, et al. (2009) Modelling the variation in performance of a population of growing pig as affected by lysine supply and feeding strategy. Animal 3, 1114-1123.

28. Rivest J (2004) Epreuve 16. Performances des animaux en station. Rapport final. Evaluation des verrats terminaux: Duroc et P76, Centre de développement du porc du Québec Inc., Sainte Foy (Trial 16. Final report. Animal performance at testing station. Terminal sire evaluation: Duroc and P76, Centre of pig development of Quebec Inc., Sainte Foy).

29. Knap PW \& Rauw WM (2008) Selection for high production in pigs. In Resource Allocation Theory Applied to Farm Animal Production, pp. 210-229 [PW Knap and WM Rauw, editors]. Wallingford, Oxon: CAB International.

30. Doeschl-Wilson AB, Knap PW, Kinghorn BP, et al. (2007) Using mechanistic animal growth models to estimate genetic parameters of biological traits. Animal 1, 489-499.

31. Emmans GC \& Kyriazakis I (2001) Consequences of genetic change in farm animals on food intake and feeding behaviour. Proc Nutr SOC 60, 115-125.

32. Agra-net (2013) The Public Ledger Price graphs. https://www. agra-net.com/portal2/pl/plgt.jsp (accessed November 2013).

33. Sullivan BP (2007) Genetic sources of variability in pig production. Adv Pork Prod 18, 131-137.

34. British Society Animal Science (2003) Chapter 6-Macrominerals. In Nutrient Requirement Standards for Pigs, pp. 74-81 [CT Whittemore, JM Hazzledine and HW Close, editors]. Penicuik: BSAS,

35. Ru YJ, Hughes RJ \& Choct M (2003) Variation in nutritive value of commercial broiler diets. Asian-Aust J Anim Sci 16, 830-836.

36. Pastuszewska B, Tuśnio A, Taciak M, et al. (2009) Variability in the composition of potato protein concentrate produced in different starch factories - a preliminary survey. Anim Feed Sci Tech 154, 260-264.

37. NRC (2012) Minerals. In Nutrient Requirement of Swine, 11th ed., pp. 74-103. Washington, DC: National Academies Press

38. Reese D \& Brumm M (1992) G88-892 mixing quality pig feed. Historical Materials from University of Nebraska-Lincoln. 
http://digitalcommons.unl.edu/cgi/viewcontent.cgi?article=2376 \&context=extensionhist (accessed April 2013).

39. Patience JF, Thacker PA \& de Lange CFM (1995) Diet processing and delivery. In Swine Nutrition Guide, 2nd ed., pp. 215-227 [JF Patience, PA Thacker and CFM de Lange, editors]. Saskatoon: Prairie Swine Centre.

40. Simpson G (2000) Common mill calibration problems: how to avoid them on your farm. OMAFRA Factsheet, Ontario. http:// www.omafra.gov.on.ca/english/livestock/swine/facts/info_n_ common.htm (accessed November 2013).

41. McCoy RA, Behnke KC, Hancock JD, et al. (1994) Effects of mixing uniformity on broiler chick performance. Poult Sci $\mathbf{7 3}$, 433-451.
42. Patience JF, Zijlstra RT \& Beaulieu D (2002) Feeding growing and finishing pigs to maximize net income. Adv Pork Prod 13, pp. 61-75.

43. Patience FJ \& Beaulieu AD (2006) Variation in the finishing barn. Manitoba Swine Seminar, Winnipeg, MB. http://www. prairieswine.com/pdf/2244.pdf (accessed March 2013).

44. Douglas SL, Edwards SA \& Kyriazakis I (2014) Management strategies to improve the performance of low birth weight pigs to weaning and their long-term consequences. J Anim Sci $\mathbf{9 2}$, 2280-2288

45. Douglas SL, Wellock IJ, Edwards SA, et al. (2014) High specification diets improve the performance of low birth weight pigs to 10 weeks of age. J Anim Sci 92, 4741-4750. 